\title{
Determination of the Stable Area And Parameters OPTIMIZATION OF SINTERED CARBIDE MACHINING BY WEDM
}

\author{
Vladimír Šimna, Martin Necpal, Tomáš Vopát \& Marcel Kuruc
}
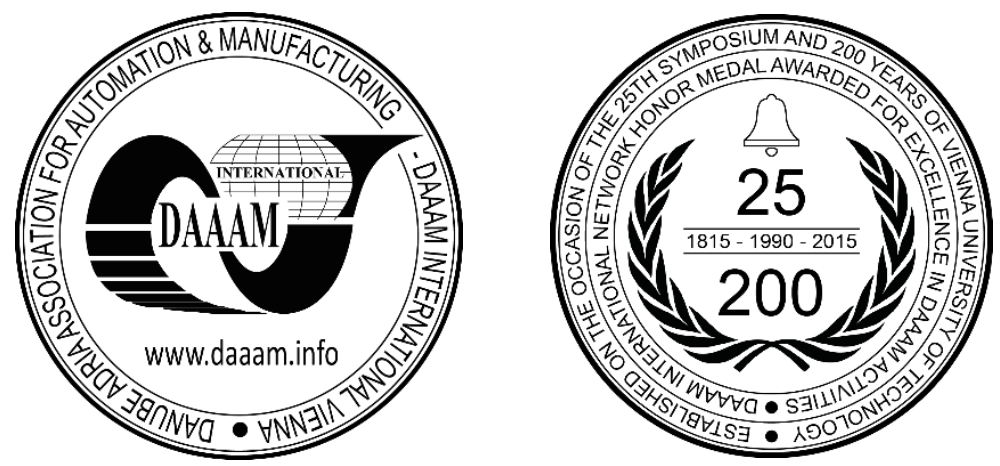

This Publication has to be referred as: Simna, V[ladimir]; Necpal, M[artin]; Vopat, T[omas] \& Kuruc, M[arcel] (2018). Determination of the Stable Area and Parameters Optimization of Sintered Carbide Machining by WEDM, Proceedings of the 29th DAAAM International Symposium, pp.0752-0761, B. Katalinic (Ed.), Published by DAAAM International, ISBN 978-3-902734-20-4, ISSN 1726-9679, Vienna, Austria

DOI: $10.2507 / 29$ th.daaam.proceedings.109

\begin{abstract}
The article is divided into two main experimental parts. The screening experiment setting is described in the first part and settings of the main experiment is described in the second part. The aim was to clarify the impact of input parameters on the cutting process and to find those parameters to make the process as fast and stable as possible. Sintered carbide type K (PCG GMBH F10) was used as the sample. The experiment was performed on the machine Agie Charmilles Robofil 310. As input factors were selected pulse width, the time between two pulses, servo voltage, pulse current, short pulse time and frequency. Due to the fact that it is necessary to assess the impact of several input parameters, the Taguchi experimental design was selected. L27 matrix was used. Screening experiment was used in the first part of the experiment.
\end{abstract}

Keywords: material removal rate; WEDM; ANOVA; sintered carbide

\section{Introduction}

The aim of the publication is to provide a stable area for the machining of sintered carbides by WEDM. This means finding the area where machining will be the fastest and most stable. Material Removal Rate (MRR) is generally expressed as a proportion of the volume of removed material and time for which it has been taken. Sometimes it is expressed as a weight of removed material for a time. In the case of EDM wire cutting, for the calculation is most commonly used formula [1]:

$$
\mathrm{MRR}=\mathrm{v}_{\mathrm{c}} \cdot \mathrm{B} \cdot \mathrm{H}\left[\mathrm{mm}^{3} \cdot \mathrm{min}^{-1}\right]
$$

The basic parameters of wire EDM can be considered following: pulse on time, pulse off time, voltage, peak current, discharge current, flushing pressure of the dielectric fluid, wire feed rate, and wire tension. Each of these parameters (except wire tension and wire feed rate) has a huge influence on the cutting process, which is explained in detail in [2]. 
Pulse on time can be characterized as the time that the generator delivers energy to the process (during which the material is removed from the workpiece). Pulse off time a non-zero pulse off time is a necessary requirement for WEDM operation. Discharge between the electrodes leads to ionization of the spark gap. Before another spark can take place, the medium must de-ionize and regain its dielectric strength. This takes some finite time, and power must be switched off during this time. Too low values of pulse-off time may lead to short-circuits and arcing. A large value, on the other hand, increases the overall machining time since no machining can take place during the off-time. The MRR is found to depend strongly on the spark frequency. When high-frequency sparks are used lower values of MRR are observed. It is so because the energy available in a given amount of time is shared by a larger number of sparks leading to shallower discharge craters. Peak current is one of the primary input parameters of a WEDM process and the amount of current used is measured using ammeter during the process. In discharge machining, usually very high currents are not used as they often lead to high heat which damage of the work surface, the depth of the recast layer, workpiece might become hardened than its parent material and so on. In other words, the stronger the discharge current, the higher will be the material removal rate, over-cut and surface roughness, but decreased the electrode wear rate. The discharge current is a measure of the power supplied to the discharge gap. A higher current leads to higher pulse energy and formation of deeper discharge craters. This increases the material removal rate (MRR) value. A similar effect on MRR is produced when the gap voltage is increased. Flushing Pressure of Dielectric apart from the electrical parameters, the pressure of the dielectric may have an effect on the process performance during WEDM. The velocity of the dielectric jet is directly proportional to the inlet dielectric pressure. A high-velocity gas jet would lead to better flushing of debris from the discharge gap thus improving the MRR values. Forced flow of dielectric also helps in reducing the time required for recovery of dielectric strength of the medium since the fresh and previously non-ionized medium is continuously supplied to the gap [7].

Research on the relationship between the cutting speed and input parameters has been described in [3]. The cemented carbide has been machined. It has been found that the increase of pulse duration leads to a higher cutting speed, greater duration of the pulse off time, the more cutting speed decreases and the voltage affects the cutting speed inversely and with increasing discharge current cutting speed increases. This is shown in the figure 1.
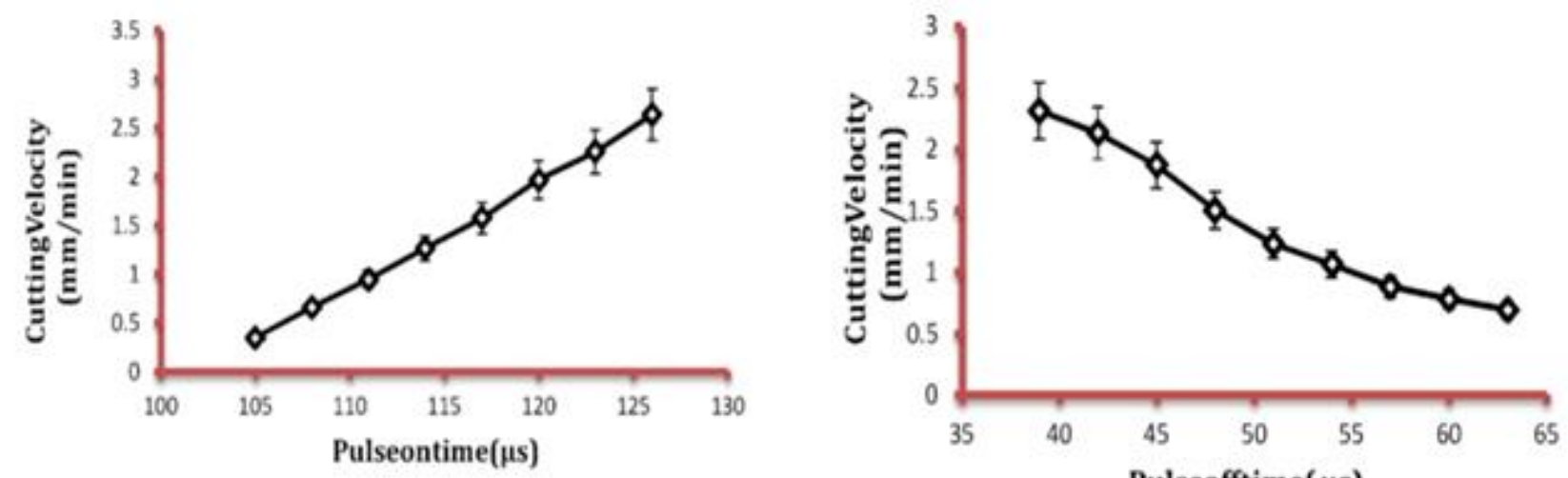

Fig. 1. Scatter plot which demonstrates the effects of a pulse on time on cutting velocity [3]

It was found that the discharge current and the discharge pulse duration have a greater impact than other observed parameters on the MRR, surface roughness and electrode wear [4]. In [5] has been proved, discharge frequency, voltage, pulse duration, and wire feed rate has the greatest influence on the MRR. S. R. NITHIN ARAVIND et al. [6] presents the experimental study to select the best suitable value of voltage, current, speed, pulse on/off time in order to get maximum material removal rate (MRR) and minimum surface roughness (SR).

\section{Methods and materials}

As workpiece material, sintered carbide PCG GMBH F10 was used. This is a cemented carbide with a fine structure where the main component is tungsten carbide in a cobalt matrix, and it is included in $\mathrm{K}$ group. The experiment was carried out on the Charmilles ROBOFIL 310 machine, which is a CNC machine for wire EDM. The diameter of the $\mathrm{CuZn} 37$ wire was $0.25 \mathrm{~mm}$. Wire tensile strength Re was $980 \mathrm{~N} . \mathrm{mm}^{-2}$. As dielectricum deionized water was used. The conductivity of the dielectricum was $5 \mu \mathrm{S}$. For this work, Taguchi's design experiment was chosen as an incomplete experiment design that provided relevant results. Orthogonal matrix L27 will be used.

\subsection{Screening experiment setup}

This experiment was necessary because ANOVA was unable to work with unmeasured data. Therefore, it is essential for each measurement to measure a material removal rate without breaking the electrode. 
Breakage of the electrode is also a relevant result, and the detection of the area in which the electrode is interrupted is at least as important as detecting the influence of the parameters on the MRR, but the breakage of the electrode cannot be expressed numerically. Factor levels set in the screening experiment were chosen to the maximum extent possible for the machine to determine when the cutting process is sufficiently stable. The factors and their levels for the screening experiment are shown in Tab. 1.

\begin{tabular}{|c|c|c|c|c|c|}
\hline \multirow{2}{*}{ Parameter } & \multirow{2}{*}{ Symbol } & \multirow{2}{*}{ Unit } & \multicolumn{3}{|c|}{ Levels } \\
\cline { 4 - 6 } & & $\mathrm{L} 1$ & $\mathrm{~L} 2$ & $\mathrm{~L} 3$ \\
\hline Pulse width & $\mathrm{A}$ & $\mu \mathrm{s}$ & 0,4 & 0,7 & 1 \\
\hline $\begin{array}{c}\text { The time } \\
\text { between two } \\
\text { pulses }\end{array}$ & $\mathrm{B}$ & $\mu \mathrm{s}$ & 16 & 20 & 24 \\
\hline Servo voltage & $\mathrm{Aj}$ & $\mathrm{V}$ & 30 & 40 & 50 \\
\hline Wire speed & $\mathrm{Ws}$ & $\mathrm{m} / \mathrm{min}$ & 5 & 10 & 15 \\
\hline $\begin{array}{c}\text { Short pulse } \\
\text { time }\end{array}$ & $\mathrm{TAC}$ & $\mu \mathrm{s}$ & 0,2 & 0,3 & 0,4 \\
\hline Frequency & $\mathrm{FF}$ & $\%$ & 50 & 75 & 100 \\
\hline
\end{tabular}

Table 1. Factor levels setting in the screening experiment

After the electrode break, the experiment was repeated with the same factor setting in order to eliminate the rupture error due to the failure of the wire material or other accidental external influences. In the Fig. 2 screening experiment sample can be seen. It is possible to notice that each cut has a different depth. This is because, in some cases, machining was stable. Extremely unstable area means measurements were not even cut, since the wire was ruptured after a very short time from cutting. The remaining sections belong to the group where the wire breaks up after a longer period of time.

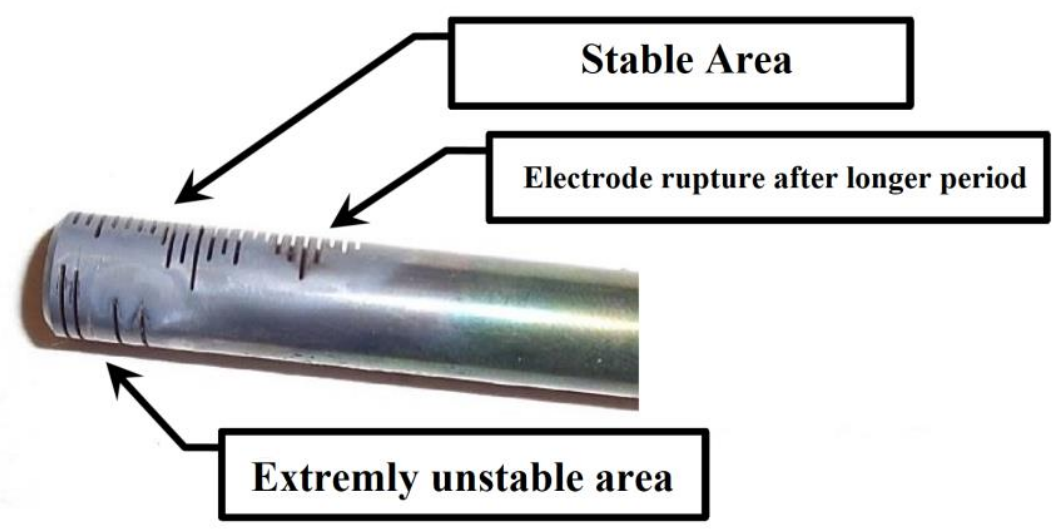

Fig 2. Screening experiment sample

All measured values of the screening experiment are shown in the tab. 2

\begin{tabular}{|c|c|c|c|c|c|c|c|}
\hline \multirow{2}{*}{ Number } & \multicolumn{6}{|c|}{ Parameters } & \multirow{2}{*}{ Stability } \\
\hline & $\mathrm{A}$ & $\mathrm{B}$ & $\mathrm{Aj}$ & Ws & TAC & $\mathrm{FF}$ & \\
\hline 1 & 0,4 & 16 & 30 & 5 & 0,2 & 50 & Stable \\
\hline 2 & 0,4 & 16 & 30 & 5 & 0,3 & 75 & Stable \\
\hline 3 & 0,4 & 16 & 30 & 5 & 0,4 & 100 & Stable \\
\hline 4 & 0,4 & 20 & 40 & 10 & 0,2 & 50 & Stable \\
\hline 5 & 0,4 & 20 & 40 & 10 & 0,3 & 75 & Stable \\
\hline 6 & 0,4 & 20 & 40 & 10 & 0,4 & 100 & Stable \\
\hline 7 & 0,4 & 24 & 50 & 15 & 0,2 & 50 & Stable \\
\hline 8 & 0,4 & 24 & 50 & 15 & 0,3 & 75 & Stable \\
\hline
\end{tabular}




\begin{tabular}{|c|c|c|c|c|c|c|c|}
\hline 9 & 0,4 & 24 & 50 & 15 & 0,4 & 100 & Stable \\
\hline 10 & 0,7 & 16 & 40 & 15 & 0,2 & 50 & Stable \\
\hline 11 & 0,7 & 16 & 40 & 15 & 0,3 & 75 & Stable \\
\hline 12 & 0,7 & 16 & 40 & 15 & 0,4 & 100 & Stable \\
\hline 13 & 0,7 & 20 & 50 & 5 & 0,2 & 50 & Unstable \\
\hline 14 & 0,7 & 20 & 50 & 5 & 0,3 & 75 & Unstable \\
\hline 15 & 0,7 & 20 & 50 & 5 & 0,4 & 100 & Stable \\
\hline 16 & 0,7 & 24 & 30 & 10 & 0,2 & 50 & Stable \\
\hline 17 & 0,7 & 24 & 30 & 10 & 0,3 & 75 & Stable \\
\hline 18 & 0,7 & 24 & 30 & 10 & 0,4 & 100 & Stable \\
\hline 19 & 1 & 16 & 50 & 10 & 0,2 & 50 & Unstable \\
\hline 20 & 1 & 16 & 50 & 10 & 0,3 & 75 & Unstable \\
\hline 21 & 1 & 16 & 50 & 10 & 0,4 & 100 & Unstable \\
\hline 22 & 1 & 20 & 30 & 15 & 0,2 & 50 & Unstable \\
\hline 23 & 1 & 20 & 30 & 15 & 0,3 & 75 & Stable \\
\hline 24 & 1 & 20 & 30 & 15 & 0,4 & 100 & Unstable \\
\hline 25 & 1 & 24 & 40 & 5 & 0,2 & 50 & Unstable \\
\hline 26 & 1 & 24 & 40 & 5 & 0,3 & 75 & Unstable \\
\hline 27 & 1 & 24 & 40 & 5 & 0,4 & 100 & Unstable \\
\hline
\end{tabular}

Table 2. Measured values of the screening

From the Table 2. is obvious the pulse width A will probably most influence the breakage of the electrode. For better interpretation of the electrode rupture, see figure 3.

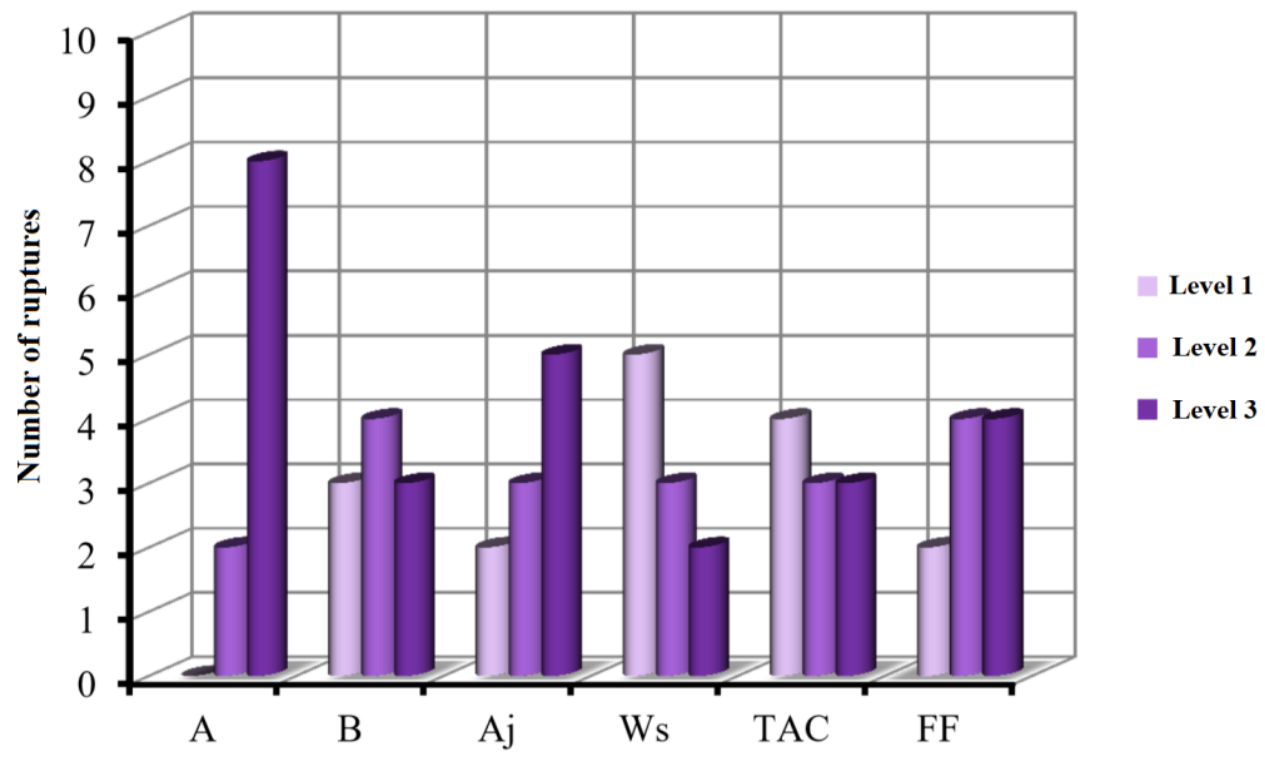

Fig. 3. Dependence on the amount of electrode breakage on individual factors

At the first level of the pulse width A, the electrode was not ruptured. At the second level, the electrode was ruptured 2 times and at the third level up to 8 times a total of 10 ruptures.

This means that increasing the pulse width increases the rupturing of the electrode very rapidly and exponentially (see Figure 4). If the width of the cut (A) is set to 0.7, it can be assumed that this level is close to the boundary of the area where the wire begins to rupture. The pulse width is, therefore, the riskiest factor in the view of the rupturing of the electrode and its magnitude must be minimized to ensure the success of the final experiment as much as possible. It should definitely be less than $0.7 \mu$ s. 


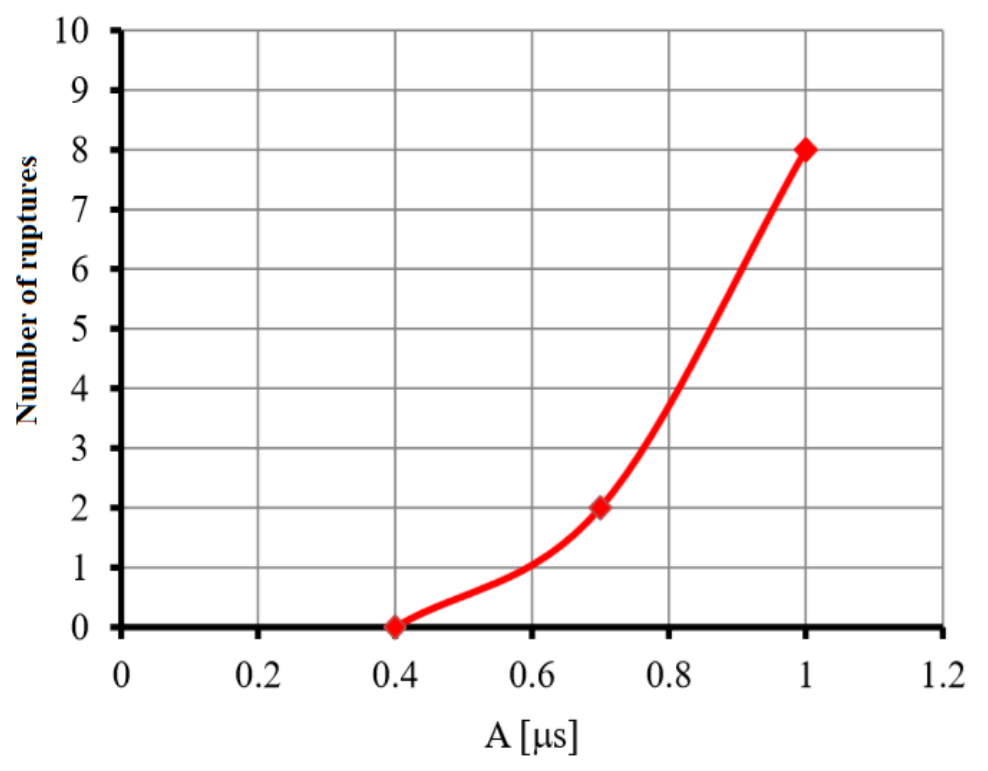

Fig. 4. The dependence of the number of wire breaks on the pulse width

\section{Results}

The measurement was carried out without breaking the wire, which implies that the process was stable throughout the experiment and the measurement was successful. It was found that the boundary of the area in which our wire does not break in our conditions is pulse width $0,6 \mu \mathrm{s}$.

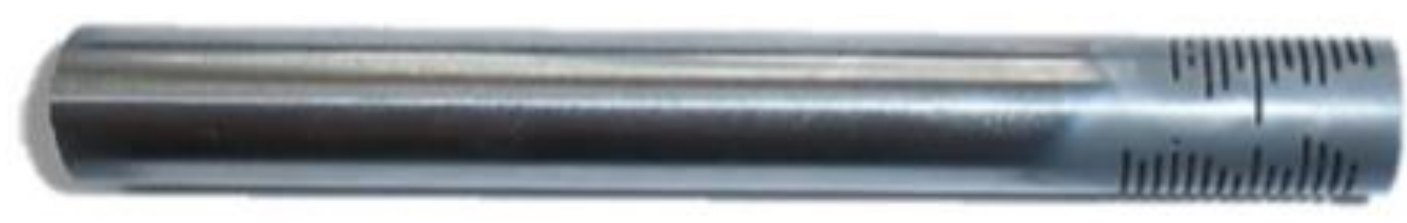

Fig. 5. Sample after the final experiment

Taguchi method uses the $\mathrm{S} / \mathrm{N}$ ratio to measure characteristic deviating from the desired value. The $\mathrm{S} / \mathrm{N}$ ratio is the ratio of the mean to the standard deviation. Taguchi method suggests that the signal to noise ratio $(\mathrm{S} / \mathrm{N})$ can be used as a quantitative analysis tool. [10] When evaluating the experiment, the measured MRR values and the signal to noise ratio are used as a response. The signal / noise ratio means how the response changes with respect to the target value under different noise conditions. According to the experiment goal, we can choose the $\mathrm{S} / \mathrm{N}$ ratio for the following cases:

a) Larger is better

$\mathrm{S} / \mathrm{N}_{\text {bigger }}=-10 \log _{10}\left[\frac{\sum_{i=1}^{n}\left(\frac{1}{y_{1}}\right)^{2}}{n}\right]$,

b) Smaller is better

$\mathrm{S} / \mathrm{N}_{\text {smaller }}=-10 \log _{10}\left[\frac{\sum_{i=1}^{n}\left(y_{i}\right)^{2}}{n}\right]$,

c) Nominal is better

$$
\mathrm{S} / \mathrm{N}_{\text {nominal }}=-10 \log _{10}\left[\frac{\sum_{i=1}^{n}(\bar{y})^{2}}{s^{2}}\right] \text {, }
$$

where $\mathrm{n}$ is the number of repeats, $\underline{\mathrm{y}}_{\mathrm{i}}$ is the measured value of the desired characteristic, $\bar{y}$ is the mean of the measured values and $\mathrm{s}^{2}$ is the variance [8]. The goal of this experiment is to maximize MRR and therefore the first option was chosen. The signal-to-noise ratio is higher because the Taguchi design itself is primarily designed to analyse these values. In tab. 3, the MRR values for each $\mathrm{N}$-th measurement are read from the machine as well as the $\mathrm{S} / \mathrm{N}$ ratio calculated in Minitab software. 


\begin{tabular}{|c|c|c|c|c|c|c|c|c|}
\hline \multirow{2}{*}{ Number } & \multicolumn{6}{|c|}{ Parameters } & \multirow{2}{*}{$\begin{array}{c}\text { MRR } \\
{[\mathrm{mm} / \mathrm{min}]}\end{array}$} & \multirow{2}{*}{$\begin{array}{c}\text { SN ratio } \\
{[\mathrm{dB}]}\end{array}$} \\
\hline & $\mathrm{A}$ & $\mathrm{B}$ & $\mathrm{Aj}$ & Ws & $\mathrm{TAC}$ & $\mathrm{FF}$ & & \\
\hline 1 & 0,4 & 16 & 30 & 5 & 0,2 & 50 & 9,9 & 19,9127 \\
\hline 2 & 0,4 & 16 & 30 & 5 & 0,3 & 75 & 14,9 & 23,4637 \\
\hline 3 & 0,4 & 16 & 30 & 5 & 0,4 & 100 & 19,8 & 25,9333 \\
\hline 4 & 0,4 & 20 & 40 & 10 & 0,2 & 50 & 7,8 & 17,8419 \\
\hline 5 & 0,4 & 20 & 40 & 10 & 0,3 & 75 & 12,2 & 21,7272 \\
\hline 6 & 0,4 & 20 & 40 & 10 & 0,4 & 100 & 15 & 23,5218 \\
\hline 7 & 0,4 & 24 & 50 & 15 & 0,2 & 50 & 5,7 & 15,1175 \\
\hline 8 & 0,4 & 24 & 50 & 15 & 0,3 & 75 & 7,8 & 17,8419 \\
\hline 9 & 0,4 & 24 & 50 & 15 & 0,4 & 100 & 10 & 20 \\
\hline 10 & 0,7 & 16 & 40 & 15 & 0,2 & 50 & 14,2 & 23,0458 \\
\hline 11 & 0,7 & 16 & 40 & 15 & 0,3 & 75 & 18 & 25,1055 \\
\hline 12 & 0,7 & 16 & 40 & 15 & 0,4 & 100 & 11,9 & 21,5109 \\
\hline 13 & 0,7 & 20 & 50 & 5 & 0,2 & 50 & 10,8 & 20,6685 \\
\hline 14 & 0,7 & 20 & 50 & 5 & 0,3 & 75 & 13,6 & 22,6708 \\
\hline 15 & 0,7 & 20 & 50 & 5 & 0,4 & 100 & 8,2 & 18,2763 \\
\hline 16 & 0,7 & 24 & 30 & 10 & 0,2 & 50 & 12 & 21,5836 \\
\hline 17 & 0,7 & 24 & 30 & 10 & 0,3 & 75 & 15,9 & 24,0279 \\
\hline 18 & 0,7 & 24 & 30 & 10 & 0,4 & 100 & 10,4 & 20,3407 \\
\hline 19 & 1 & 16 & 50 & 10 & 0,2 & 50 & 17,5 & 24,8608 \\
\hline 20 & 1 & 16 & 50 & 10 & 0,3 & 75 & 11,8 & 21,4376 \\
\hline 21 & 1 & 16 & 50 & 10 & 0,4 & 100 & 15,7 & 23,918 \\
\hline 22 & 1 & 20 & 30 & 15 & 0,2 & 50 & 18 & 25,1055 \\
\hline 23 & 1 & 20 & 30 & 15 & 0,3 & 75 & 13,2 & 22,4115 \\
\hline 24 & 1 & 20 & 30 & 15 & 0,4 & 100 & 19 & 25,5751 \\
\hline 25 & 1 & 24 & 40 & 5 & 0,2 & 50 & 18,2 & 25,2014 \\
\hline 26 & 1 & 24 & 40 & 5 & 0,3 & 75 & 10,7 & 20,5877 \\
\hline 27 & 1 & 24 & 40 & 5 & 0,4 & 100 & 14,9 & 23,4637 \\
\hline
\end{tabular}

Table 3. Measured and calculated values

ANOVA is a generalization of the Student t-test for independent choices. It examines the effect of the factors on the investigated response. In the following tables, an ANOVA is calculated for the individual influence of individual factors on MRR for the significance level $\alpha=0.05$.

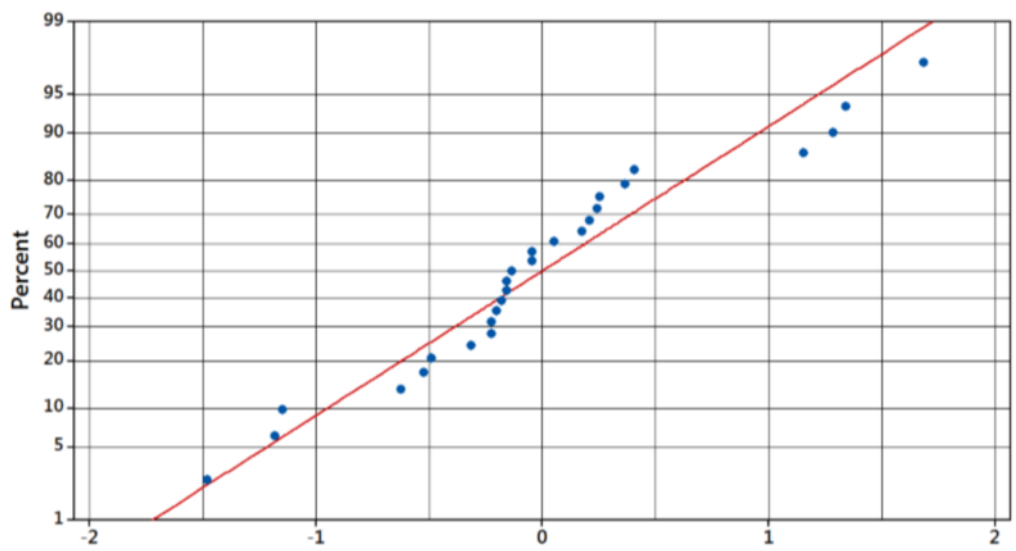

Fig. 6. The normal probability distribution of the measured value 


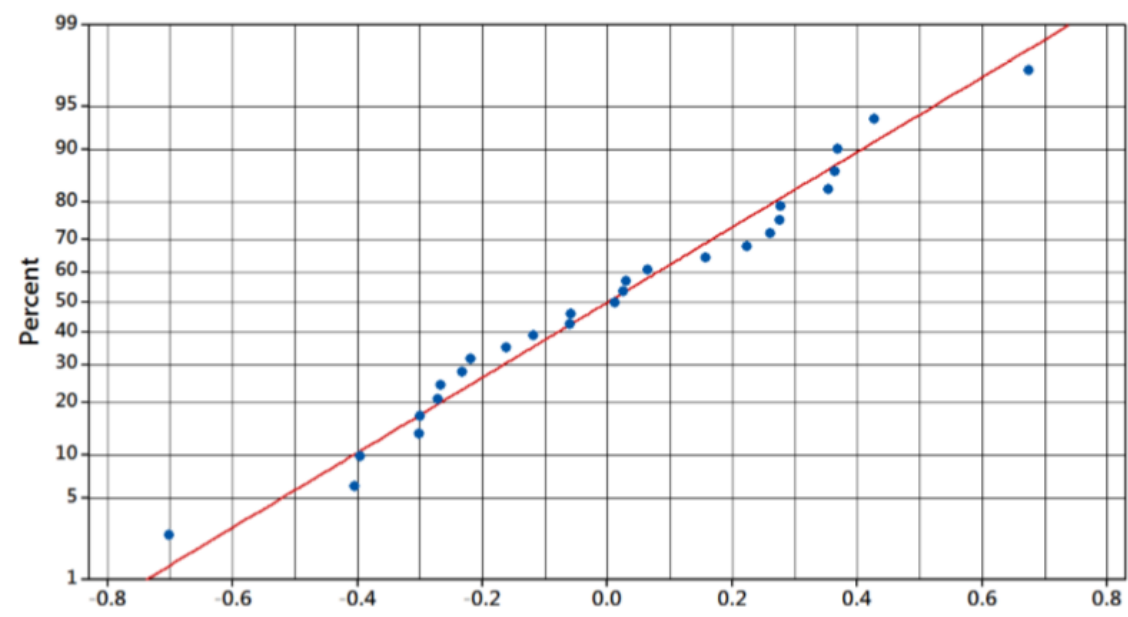

Fig. 7. The normal probability distribution of the $\mathrm{S} / \mathrm{N}$ ratio

If the value $P$ is less than 0.05 , the factor is statistically significant (at the level of significance $\alpha$ ). In order to perform an ANOVA analysis, it is first necessary to determine whether the measured values and the signal to noise ratio meet the normal probability distribution. For this finding, figure 6 and figure 7 were constructed.

\begin{tabular}{|c|c|c|c|c|c|c|}
\hline Factors & DF & Seq SS & Adj SS & Adj MS & F & P \\
\hline A & 2 & 41,328 & 41,328 & 20,6638 & 110,48 & 0 \\
\hline B & 2 & 24,613 & 24,613 & 12,3064 & 65,79 & 0 \\
\hline Aj & 2 & 33,031 & 33,301 & 16,5155 & 88,3 & 0 \\
\hline Ws & 2 & 1,235 & 1,235 & 0,6176 & 3,3 & 0,067 \\
\hline TAC & 2 & 4,837 & 4,837 & 2,4183 & 12,93 & 0,001 \\
\hline FF & 2 & 85,863 & 85,863 & 42,9313 & 229,53 & 0 \\
\hline
\end{tabular}

Table 4. ANOVA for S/N ratio

Statistically significant parameters with respect to the measured data (at the level of significance $\alpha=0,05$ ) are parameters $\mathrm{A}, \mathrm{B}, \mathrm{Aj}, \mathrm{TAC}$, and $\mathrm{FF}$. The $\mathrm{Ws}$ parameter is shown to be statistically insignificant because its $\mathrm{P}=0.067$ value is more than 0.05 .

\begin{tabular}{|c|c|c|c|c|c|c|}
\hline Factors & DF & Seq SS & Adj SS & Adj MS & F & P \\
\hline A & 2 & 74,321 & 74,312 & 37,1559 & 36,43 & 0 \\
\hline B & 2 & 44,121 & 44,121 & 22,0604 & 21,63 & 0 \\
\hline Aj & 2 & 59,381 & 59,381 & 29,6904 & 29,11 & 0 \\
\hline Ws & 2 & 0,659 & 0,659 & 0,3293 & 0,32 & 0,729 \\
\hline TAC & 2 & 6,625 & 6,625 & 3,3126 & 3,25 & 0,069 \\
\hline FF & 2 & 177,734 & 177,734 & 88,867 & 87,12 & 0 \\
\hline
\end{tabular}

Table 5. ANOVA for MRR

Significant signal/noise ratio parameters (at the significance level $\alpha=0,05$ ) are parameters of the pulse width A, the time between two pulses B, servo voltage $\mathrm{Aj}$, and the frequency FF. The Ws parameter is as statistically insignificant as in the previous case because its value $\mathrm{P}=0.729$ is more than 0.05 . In contrast to the variance analysis for measured data, however, the short pulse time TAC, whose value $\mathrm{P}=0.069$, proved to be statistically insignificant.

\subsection{Optimal Factor Setting}

To find out the effects in response, the Main Effects Plot chart. These graphs explain whether there is a direct or indirect dependence between a given parameter and a response. As in previous cases, one chart for the values will be measured and the other for the signal / noise ratio. 


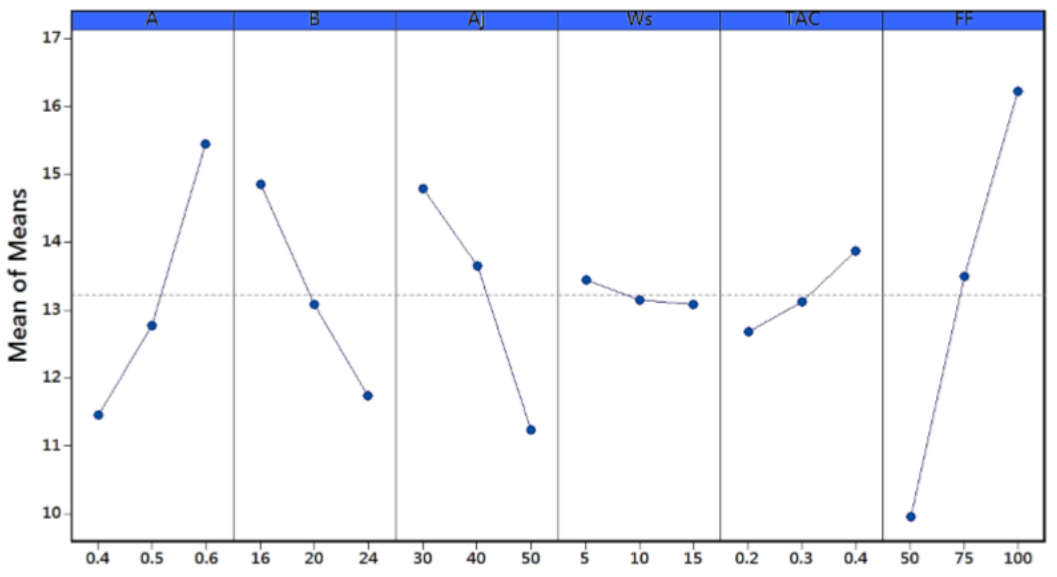

Fig. 8. Dependence of MRR on factors setting

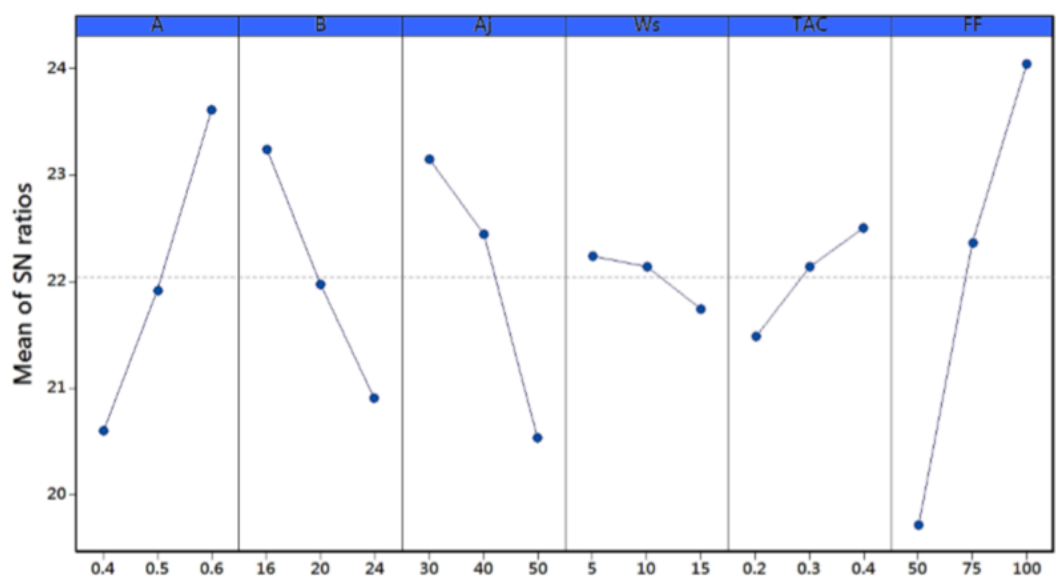

Fig. 9. Dependence of MRR on factors setting

From the graphs, increasing the pulse width A, the short pulse time TAC and the FF frequency is increasing. On the contrary, by increasing the parameters between the two pulses B, the mean reference voltage of the servo drive A and the wire unwinding rate Ws decreases. The greatest difference between the two graphs is during Ws and TAC, which have opposite convexity / concavity. Since the essence of this experiment is to maximize MRRs and graphs, it can be determined that the greatest amount of material removing in the measurement range under given conditions is in the following optimal setting of factors:

- $\mathrm{A}=0,6($ Level 3)

- $\quad \mathrm{B}=16($ Level 1)

- $\quad \mathrm{Aj}=30($ Level 1$)$

- $\quad \mathrm{Ws}=5($ Level 1$)$

- $\quad \mathrm{TAC}=0,4($ Level 3)

- $\quad \mathrm{FF}=100($ Level 3)

Response tables are a tool to help you sort factors by the magnitude of their impact on the responding response. Table 6 was created for the measured values.

\begin{tabular}{|c|c|c|c|c|c|c|}
\hline Level & $\mathrm{A}$ & $\mathrm{B}$ & $\mathrm{Aj}$ & $\mathrm{Ws}$ & $\mathrm{TAC}$ & $\mathrm{FF}$ \\
\hline 1 & 11,456 & 14,856 & 14,789 & 13,444 & 12,678 & 9,956 \\
\hline 2 & 12,778 & 13,089 & 13,656 & 13,114 & 13,122 & 13,5 \\
\hline 3 & 15,444 & 11,733 & 11,233 & 13,089 & 13,878 & 16,2 \\
\hline Delta & 3,989 & 3,122 & 3,556 & 0,356 & 1,2 & 6,267 \\
\hline Order & 2 & 4 & 3 & 6 & 5 & 1 \\
\hline
\end{tabular}

Table 6. Response table for the measured values 
The greatest influence on the material removal rate (MRR) was found at the frequency (FF), followed by the pulse width $(A)$, the average reference voltage $(A j)$, the time between two pulses $(B)$, the short pulse time (TAC), and finally the unwinding rate of the wire (Ws).

\section{Conclusion}

Performing the screening experiment determined the area of stable conditions for the subsequent final experiment, from which the results of the individual parameters were determined on the MRR. Finally, optimal parameters settings for the cutting process were determined.

Pulse width (A) had a significant impact on MRR, and its response rate was $20 \%$, the second highest. This result is in line with the findings published by Shayan, Afza and Teimouri [3], except that a higher share for the time between two pulses has been published in the papers. Interactions with A show all factors except frequency. In particular, the joint pulse width with the time between two pulses went as expected, confirming the results of Yuan and the team [9]. It can be said that even with sintered carbides, the increase in pulse width increases the intensity of the material removal rate. The optimal value of this parameter is $0.6 \mu \mathrm{s}$.

The time between two pulses (B) does not fully correspond to the results of Sharma, Khanna, Gupta [1], or other authors since its effect is approximately half that of the effect of the time between the two pulses. On the contrary, it has been confirmed that this parameter has a statistically significant impact on MRR and that its increasing material removal rate decreases. At the same time, it exhibits interaction with pulse width, mean reference voltage of the actuator and wire unwinding rate. Its optimum value under the given conditions is $16 \mu$ s. The servo voltage (Aj) has a significant impact on MRR, which is also the third strongest influence. By increasing the intensity of the material removal rate, as Shayan, Afza and Teimouri [3] are saying. This parameter displays pulse width interactions, pulse duration, and wire unwinding rate. These findings are consistent with the information provided in the literature. The optimum value in the given conditions reaches $30 \mathrm{~V}$.

As expected, the wire unwinding rate of the Ws wire proved to be statistically insignificant. Its impact on the material removal rate did not reach $1 \%$. Unexpectedly, however, the wire unwinding rate manifested an interaction with the pulse width factors, the duration between two pulses and the servo voltage (Aj). The most surprising result, however, is the influence of the wire unwinding rate on which it was assumed that there would be direct proportionality between it and MRR. This is because the unwinding speed of the wire is to ensure a constant supply of the undamaged electrode, thereby ensuring its cohesion and electrical conductivity in the cutting process. The better electrical conductivity, the smaller the energy losses, the larger the craters and hence the higher the material removal. However, the experiment showed that at the first two levels the Ws has a very low impact on MRR, but by increasing the unwinding rate of the wire to the third level of MRR clearly decreases. This effect is in complete contradiction with the previous logic, as well as the research done by Singh and Garg [2]. There is, therefore, a limit to which the increase in wire unwinding speed is advantageous, but when it is exceeded, the high unwinding rate of the wire causes an energy barrier that is reflected by a decrease in MRR. This phenomenon would be appropriate to explore through detailed experiments and to find out what causes it, whether it occurs only with sintered carbides and what is the limit value of Ws. The optimum wire unwinding rate is $5 \mathrm{~m} / \mathrm{min}$.

The short pulse time TAC showed statistical significance, but its impact rate reached only $2.5 \%$, the second lowest value immediately after Ws. By increasing the TAC there is a slight increase in the intensity of material removal rate, which confirms the information from the expert articles. Interaction only shows the pulse width. When performing a full factor experiment, it can be assumed that it would be possible to create a pulse width - pulse joint diagram that would show the course of their joint impact on MRR. The optimal setting of this parameter is at $0.4 \mu$ s. The greatest influence on the material draw is the frequency FF. Its share of the overall result is up to $44.37 \%$. By increasing the frequency, there is a significant increase in the intensity of material removal rate. Therefore, this MRR parameter appears to be key when cutting sintered carbides. In addition, it does not show interaction with any other parameter except the TAC. As mentioned above, these findings do not match Sandeep's [7] claim that increasing the frequency of MRR decreases. It should be added that there are not many authors who would focus on FF impact research.

When investigating the boundary between the area where the process is stable and the area where the wire breaks it was found that if the pulse width does not exceed $0.6 \mu \mathrm{s}$, the wire will not break regardless of the setting of the other parameters. This result is significant, but it would be desirable to design and perform one more complete factor experiment in the future. This experiment would help determine the exact conditions in which the wire would not be pulled even at higher pulse width values, which would significantly increase the number of possible solutions.

\section{Acknowledgments}

The article was written with the support of the Project of VEGA grant agency of the Ministry of Education, Science, Research and Sport of the Slovak Republic and Slovak Academy of Sciences, no. 1/0097/17: "The research of novel method for cutting edge preparation to increase the tool performance in machining of difficult-to-machine materials", and APVV Project of Slovak Research and development Agency of the Ministry of Education, Science, Research and Sport of the Slovak Republic, no. APVV-16-0057: "Research into the Unique Method for Treatment of Cutting Edge Microgeometry by Plasma Discharges in Electrolyte to Increase the Tool Life of Cutting Tools in Machining of Difficultto-Machine Materials." 


\section{References}

[1] Sharma, N., Khanna, R. A Gupta, R. (2013). Multi Quality Characteristics of WEDM Process Parameters with RSM. Procedia Engineering. 64.710-719. ISSN 1877- 7058.

[2] Singh, H. A Garg, R. (2009). Effects of process parameters on material removal rate in WEDM. Journal of Achievements in Materials and Manufacturing Engineering. 32(1). 70-74. ISSN 1734-8412.

[3] Shayan, A. V, Afza, R. A. A Teimouri, R. (2013). Parametric study along with selection of optimal solutions in dry wire cut machining of cemented tungsten carbide (WC-Co). Journal of Manufacturing Processes. 15(4). 644-658. ISSN 1526-6125.

[4] Ramakrishnan, R. A Karunamoorthy, L. (2006). Multi-response optimization of wire EDM operations. The International Journal of Advanced Manufacturing Technology. 29(1-2).105-112. ISSN 1433-3015.

[5] Liao, Y. S., Huang, J. T. A Su, H. C. (1996). A study on the machining-parameters optimization of wire electrical discharge machining. Journal of Materials Processing Technology. 487-793. ISSN 0924-0136.

[6] S. R. Nithin Aravind, S. Sowmyi And K. P. Yuvara (2012). Optimization of metal removal Rate and surface roughness on Wire EDM using taguchi method, IEEEInternational Conference On Advances In Engineering, Science And Management (ICAESM -2012) March 30, 31.

[7] Sandeep, Malik. (2014). Optimization Of Machining Parameters Of En24 Alloy Steel On Wedm Using Rsm. International Journal of Advanced Research in IT and Engineering. 3(3). 9-20. ISSN 2278-6244.

[8] Girmanová, Lenka A Kol. (2009). Taguchiho Robustný Dizajn. In: Nástroje A Metódy Manažérstva Kvality, Košice: Hutnícka Fakulta Technickej Univerzity V Košiciach,7-8. Isbn 978-80-553-0144-0

[9] Yuan, J., Wang, K., Yu, T. A Fang, M. (2008). Reliable multi-objective optimization of high-speed WEDM process based on Gaussian process regression. International Journal of Machine Tools \& Manufacture. 48(1). 47-60. ISSN 0890-6955.

[10] Begic-Hajdarevic, Derzija \& Pasic, Mugdim \& Cekic, Ahmet \& Mehmedovic, Muhamed. (2016). Optimization of Process Parameters for Cut Quality in CO2 Laser Cutting Using Taguchi Method. 0157-0164. 10.2507/27th.daaam.proceedings.024. 